\title{
Pelatihan Perancangan, Pembuatan, dan Penggunaan Media Adaptif bagi Guru-Guru SLB Negeri 1 Klungkung
}

\author{
Made Juniantari ${ }^{1}$, Gede Saindra Santyadiputra ${ }^{2}$, Luh Ayu Tirtayani ${ }^{3}$ \\ 1 Jurusan Matematika, Universitas Pendidikan Ganesha \\ ${ }^{2} J u r u s a n$ Teknik Informatika, Universitas Pendidikan Ganesha \\ ${ }^{3}$ Jurusan Pendidikan Dasar, Universitas Pendidikan Ganesha \\ e-mail: mdjuniantari@undiksha.ac.id
}

\begin{abstract}
Abstrak
Penyediaan layanan pendidikan yang bermutu bukanlah menjadi hak anak normal saja, tetapi juga bagi anak berkebutuhan khusus (ABK). Hasil analisis situasi di SLB Negeri 1 Klungkung menunjukkan bahwa ketersediaan media pembelajaran adaptif di sekolah masih minim padahal bagi ABK fungsi media bukan saja sebagai mediator dalam pembelajaran tetapi juga berperan sebagai alat bantu ketunaan, alat bantu terapi, dan alat bantu rehabilitasi. Bersama mitra selanjutnya disepakati prioritas masalah yang sekaligus menjadi tujuan dari program PKM ini yaitu pemberdayaan guru dalam mengidentifikasi, merancang, membuat, dan menggunakan media adaptif bagi ABK. Metode pelaksanaan kegiatan adalah pelatihan. Pelatihan melibatkan 17 orang guru SLB Negeri 1 Klungkung. Pelatihan dilaksanakan dalam 3 sesi yaitu 1) pemaparan materi tentang pentingnya pemanfaatan media adaptif untuk $A B K, 2$ latihan merancang dan membuat media, serta 3) simulasi penggunaan media yang dihasilkan. . Kegiatan pelatihan telah berhasil meningkatkan kemampuan -guru dalam merancang, membuat dan menggunakan alat peraga matematika. Hal ini dapat dilihat dari kemampuan peserta dalam menghasilkan produk alat peraga fun exercise serta kemampuan peserta dalam menggunakannya media tersebut. Peserta menanggapi positif terhadap pelaksanaan pelatihan dengan persentase skornya sebesar $88,9 \%$.
\end{abstract}

Kata kunci: pelatihan, media adaptif, anak berkebutuhan khusus, sekolah luar biasa

\begin{abstract}
Providing quality education services is not the right of normal children only, but also for children with special needs (CSN). The results of the situation analysis at SLB Negeri 1 Klungkung show that the availability of adaptive learning media in schools is still minimal, even though for children with special needs, the function of the media is not only as a mediator in learning but also as a disability aid, therapeutic aids and rehabilitation aids. Together with partners, it was agreed upon priority issues which were also the goal of this program, namely empowering teachers in identifying, designing, creating, and using adaptive media for children with special needs. The method of implementing the activity is training. The training involved 17 teachers of SLB Negeri 1 Klungkung. The training was carried out in 3 sessions, namely 1) presentation of material on the importance of using adaptive media for children with special needs, 2) training in designing and making media, and 3) simulating the use of the resulting media.. The training activities have succeeded in increasing the skills of teachers in designing, making and using mathematics teaching aids. This can be seen from the ability of the participants to produce fun exercise teaching aids and the ability of the participants to use these media. Participants responded positively to the implementation of the training with a score percentage of $88.9 \%$.
\end{abstract}

Keywords : training, adaptive media, children with special needs, special need schools 


\section{PENDAHULUAN}

Penyediaan layanan pendidikan yang bermutu bukanlah menjadi hak anak normal saja, teapi juga bagi anak berkebutuhan khusus (ABK) (Putra, Suarsana, \& Suharta, 2020; Rahmawati \& Suarsana, 2014; I M. Suarsana, Mahayukti, Sudarma, \& Yoga, 2018). Penyelenggarakan layanan pendidikan ABK dapat berupa pendidikan inklusi, integrasi dan segregasi. Pada pendidikan segregasi, ABK bersekolah terpisah dengan anak normal atau sering disebut dengan Sekolah Luar Biasa (SLB). Dalam permendiknas nomor 33 Tahun 2008 disebutkan bahwa idealnya disediakan minimum satu SDLB dan satu SMPLB untuk satu kabupaten/kota. Seluruh kabupaten/kota di provinsi Bali saat telah memiliki SLB. SLB Negeri 1 Klungkung merupakan satu-satunya SLB di Kabupaten Klungkung yang berlokasi di Jalan Dewi Sartika Nomor 5 Semarapura. Pada semester ganjil tahun pelajaran 2019/2020 SLB Negeri 1 Klungkung memiliki 38 Rombel dari kelas I hingga kelas XI dengan jumlah siswa keseluruhannya adalah 108 orang (SD: 72 orang, SMP: 23 orang, SMA: 13 orang). Siswa dengan ketunaan yang sama dikelompokkan dalam 1 rombel, dan berdasarkan ketunaannya dapat diuraikan distribusi rombel sebagai mana tertera pada Tabel 1.

Dari 108 siswa di SLB Negeri 1 Klungkung, sebanyak 59 orang (55\%) merupakan siswa tuna grahita, 35 orang $(32 \%)$ adalah siswa tuna rungu, dan sisanya $13 \%$ adalah siswa tuna netra, siswa tuna daksa, dan siswa autis.

Strategi pembelajaran $A B K$ sangat bergantung pada kekhususan siswanya agar potensi siswa dapat berkembang optimal (Mais, 2018). Optimalisasi pembelajaran dapat tercapai bila guru memiliki pemahaman yang memadai tentang media pembelajaran karena bagi ABK, fungsi media bukan saja sebagai mediator dalam pembelajaran tetapi juga berperan sebagai alat bantu ketunaan, alat bantu terapi, dan alat bantu rehabilitasi. Media pembelajaran yang disesuaikan dengan kondisi dan potensi ABK sering disebut sebagai media adaptif (Mais, 2018).
Telah dilakukan observasi pembelajaran di kelas tuna grahita dan juga kelas tuna rungu. Diperoleh bahwa dalam pembelajaran guru masih berorientasi pada buku teks saja yang didominasi guru dengan metode ekspositori (paparan). Khusus pada kelas tuna rungu, guru mengajar dengan menggunakan bahasa komunikasi total yaitu dengan menggunakan bahasa gerak tubuh, ujaran, gerak jari, dan isyarat. Pembelajaran belum difasilitasi media pembelajaran adaptif yang tentu saja sangat dibutuhkan siswa. Siswa butuh media karena keterbatasan mereka, siswa butuh media agar materi lebih mudah dipahami dan lebih nyata, dan siswa butuh media karena perkembangan kognitif mereka memang masih operasional konkrit. Bila hal ini tetap terjadi, siswa akan mengalami kesulitan belajar, bosan dan bermuara pada hasil belajar yang rendah. Dan hasil wawancara dengan guru memang diperoleh informasi yang demikian, bahwa hasil belajar di SLB masih rendah, dan juga sangat jarang mencapai target lingkup materi sesuai kurikulum, misalnya dari 4 topik pembelajaran dalam satu semester, biasanya guru hanya mampu mencapai 2 - 3 topik saja.

Salah satu penyebab belum optimalnya kualitas pembelajaran di SLB adalah belum tersedianya media pembelajaran adaptif di sekolah baik media konkrit maupun media berbasis TIK. Pemahaman dan keterampilan guru untuk merancang media pembelajaran adaptif juga sangat terbatas. Berdasarkan informasi kepala sekolah, guru-guru yang mengajar di SLB memang sebagian besar bukan lulusan pendidik PLB. Dari 19 orang guru hanya ada 2 orang telah berkualifikasi guru pendidikan luar biasa (PLB) sedangkan yang lainnya berkualifikasi $S 1$ Pendidikan Guru non PLB bahkan ada juga S1 Non Pendidikan. Jumlah guru yang telah tersertifikasi juga masih minim yaitu hanya 4 orang. Dengan demikian bisa dimaklumi bila pengetahuan dan kemampuan sebagian besar guru dalam mengidentifikasi kebutuhan media, merancang media, dan menggunakan media pembelajaran adaptif masih kurang. 
Tabel 1 Distribusi Jumlah Siswa berdasarkaan Ketunaan

\begin{tabular}{rlcc}
\hline NO & \multicolumn{1}{c}{ Ketunaan } & Banyak Rombel & Jumlah Siswa \\
\hline 1. & Tuna Netra $(\mathrm{A})$ & 4 & 5 \\
\hline 2. & Tuna Rungu (B) & 12 & 35 \\
\hline 3. & Tuna Grahita Ringan (C) & 12 & 52 \\
\hline 4. & Tuna Grahita Sedang (C1) & 2 & 7 \\
\hline 5. & Tuna Daksa Ringan (D) & 5 & 5 \\
\hline 6. & Tuna Daksa Sedang (D1) & 1 & 1 \\
\hline 7. & Autisme (F) & 2 & 3 \\
\hline & & & 108 \\
\hline
\end{tabular}

Tujuan dari kegiatan PkM ini adalah untuk memberdayakan guru dalam mengidentifikasi, merancang, membuat dan menggunakan media adaptif bagi ABK

\section{METODE}

Menindaklanjuti permasalahan yang dihadapi SLB Negeri 1 Klungkung berkaitan dengan minimnya ketersediaan media adaptif bagi ABK dan belum optimalnya kemampuan guru dalam membuat media adaptif maka dibutuhkan suatu program pengabdian kepada masyarakat dalam bentuk kegiatan pelatihan. Adapun kerangka pemecahan masalah yang ditempuh adalah sebagai berikut.
(1) Menyusun materi pelatihan tentang "Pentingnya Pemanfaatan Media Adaptif dalam Pembelajaran Matematika ABK"

(2) Melaksanakan pelatihan sesuai jadwal yang ditentukan.

(3) Guru-guru yang telah pelatihan akan mulai menggunakan alat peraga dalam pembelajaran di kelas.

(4) Di akhir program, diadakan evaluasi secara keseluruhan untuk mengetahui tingkat keberhasilan program. Evaluasi kegiatan dilaksanakan pada awal kegiatan, pada saat pelatihan, dan setelah pelatihan dengan rancangan seperti pada Tabel 2.

Tabel 2. Rancangan Evaluasi

\begin{tabular}{cllc}
\hline NO & \multicolumn{1}{c}{ KRITERIA } & \multicolumn{1}{c}{ INDIKATOR } & TOLOK UKUR \\
\hline $\mathbf{1}$ & Kesiapan materi pelatihan & $\begin{array}{l}\text { Semua materi pelatihan telah } \\
\text { tersedia }\end{array}$ & $100 \%$ \\
\hline 2. & $\begin{array}{l}\text { Pemahaman terhadap pembuatan } \\
\text { media adaptif }\end{array}$ & $\begin{array}{l}\text { Semua peserta mampu membuat } \\
\text { media adaptif }\end{array}$ & $100 \%$ \\
\hline 3. & $\begin{array}{l}\text { Pemahaman terhadap cara } \\
\text { menggunakan media adaptif }\end{array}$ & $\begin{array}{l}\text { Jumlah peserta mampu } \\
\text { memperagakan penggunaan } \\
\text { media adaptif }\end{array}$ & $95 \%$ \\
\hline
\end{tabular}

\section{HASIL DAN PEMBAHASAN Hasil}

Sebelum dilakukan kegiatan pelatihan terlebih dahulu disusun materi pelatihan berupa makalah yang didalamnya memuat materi tentang i) pendahuluan, ii) pengertian dan fungsi media adaptif, iii) pengembangan dan penggunaan media adaptif, dan iv) contoh-contoh media adaptif (Aini Mahabbati, A.Pd., 2013; Atanasius, 2016; Bermasa, 2017; Mais, 2018; Yuwono \& Utomo, n.d.). Setelah materi pelatihan tersusun, selanjutnya dilakukan kegiatan pelatihan yang bertempat di SLB Negeri 1 Klungkung. Kegiatan dilakukan secara tatap muka dan juga dilakukan tindak lanjut kegiatan melalui pendampingan menggunakan LMS Google Class Room. Sebanyak 17 orang guru terlibat dalam kegiatan ini yang seluruhnya berasal dari SLB Negeri 1 Klungkung. Acara dibuka langsung oleh Kepala SLB Negeri 1 Klungkung, Ibu Ni Made Santiniwati, S.Pd. 


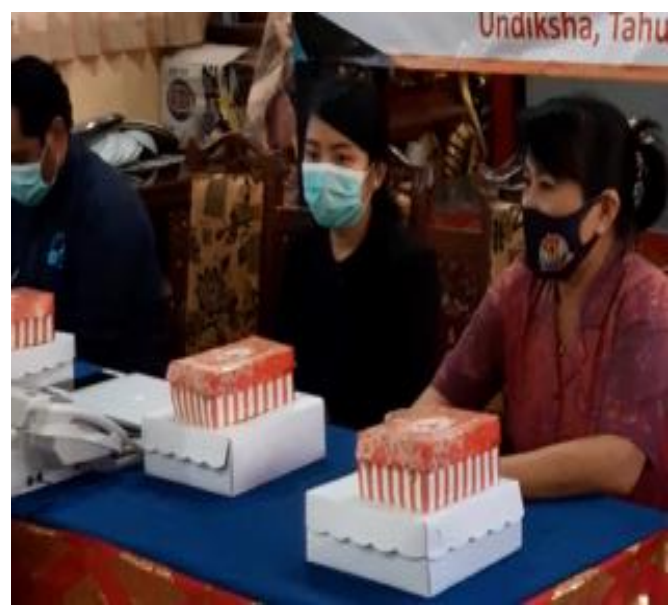

Gambar 1. Sambutan Kepala SLB N 1 Klungkung

Pelatihan diawali dengan pemaparan materi yang dibawakan oleh Narasumber Bapak I Made Suarsana, S.Pd. M.Si. Dalam paparannya beliau menyampaikan tentang pentingnya penggunakan media adaptif bagi ABK agar dapat mengotimalkan layanan belajar sesuai dengan kebutuhan khususnya. Pada kesempatan tersebut juga dipaparkan tentang fungsi dan tujuan media adaptif, prinsip-prinsip pengembangan dan penggunaannya serta menampilkan beberapa media adaptif bagi ABK.

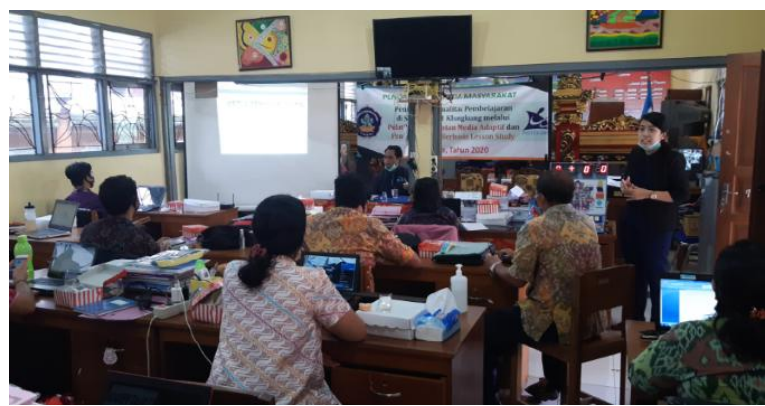

Gambar 2. Pemaparan pentingnya alat peraga

Materi pelatihan sesi berikutnya adalah praktik pembuatan media adaptif dengan dipandu tim pengabdian. Peserta dilatih untuk merancang dan media adaptif alat peraga matematika sederhana. Kegiatan dipandu oleh tim pengabdian. Peserta dikelompokkan menjadi 4 kelompok dan masing-masing membuat media Fun Exercise yaitu media adaptif konkrit yang dapat memfasilitasi siswa mengerjakan latihan soal dengan cara yang menyenangkan. Alat ini dapat digunakan utk semua $A B K$, guru perlu menyesuaikan konten/materinya saja sesuai kelas $A B K$ yang dituju.

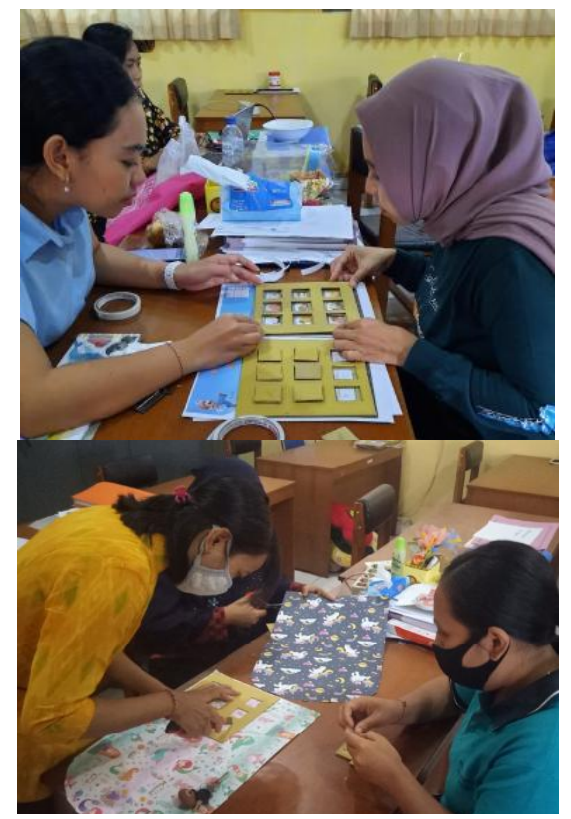

Gambar 3. Kelompok Mendiskusikan Desain Alat Peraga

Pelatihan sesi ketiga diisi dengan simulasi penggunaan media adaptif. Simulasi dilakukan untuk media yang dibawa oleh tim pengabdian dan juga media yang dihasilkan oleh peserta pelatihan. Beberapa alat peraga yang dibawa oleh tim yang sekaligus akan disumbangkan ke SLB N 1 Klungkung yaitu (1) Obiko (Operasi Bilangan dan Konversi Satuan) merupakan alat peraga untuk pembelajaran konsep operasi bilangan bulat dan konversi satuan, (2) - Paras Datar (Papan Operasi Bilangan Bulan dan Bangun Datar) merupakan alat peraga untuk penanaman konsep operasi bilangan bulat dan konsep luas bangun datar, (3) media Palu Guna (Papan Multiguna) merupakan alat peraga untuk pembelajaran konsep penjumlahan, pengurangan, pekalian dan pembagian bilangan bulat, dan konsep KPK dan FPB, (4) Media Kotak Stabil (Kotak Statistika dan Bilangan) yang dapat digunakan untuk pembelajaran statistika dan operasi bilangan bulat dan (5) media PS Box ( Kotak Pecahan dan Sudut) merupakan alat peraga untuk pembelajaran konsep pecahan dan sudut. 


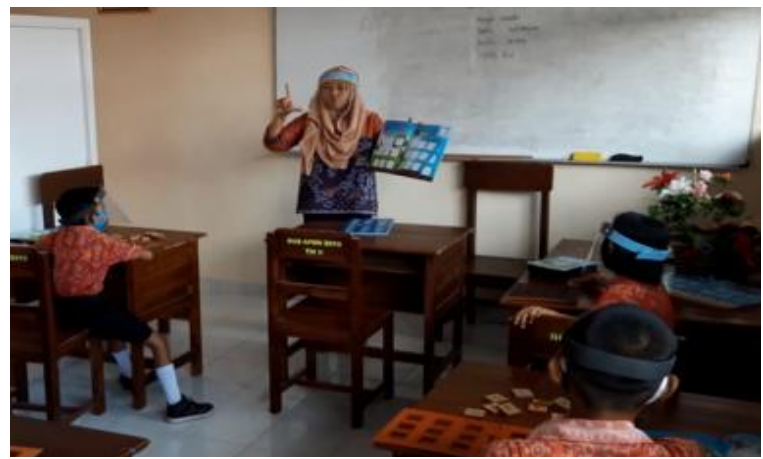

Gambar 4. Simulasi Penggunaan Alat Peraga

Selanjutnya dilakukan pula simulasi penggunaan alat peraga yang telah dibuat oleh masing-masing kelompok. Salah satunya adalah fun exercise topik lambang bilangan. Manfaat media ini adalah untuk memfasilitasi siswa mengerjakan latihan soal dengan cara yang menyenangkan. Bisa digunakan untuk semua mata pelajaran di sekolah dengan menyesuaikan soal latihannya.

Pada akhir sesi ini, dikumpulkan pula data tentang tanggapan peserta terhadap pelaksanaan kegiatan pengabdian dengan menggunakan angket dan diperoleh rata-rata skor tanggapan peserta diklat adalah 44,5 dari skor maksimum 50 atau sebesar $88.9 \%$. Adapun distribusi tanggapan peserta secara rinci tersaji pada Tabel 2.

Tabel 2. Distribusi Tanggapan Peserta

\begin{tabular}{|c|c|c|c|c|c|c|}
\hline \multirow{2}{*}{ NO } & \multirow{2}{*}{ PERNYATAAN } & \multicolumn{5}{|c|}{ TANGGAPAN } \\
\hline & & SS & $\mathbf{S}$ & $\mathbf{R}$ & TS & STS \\
\hline 1 & $\begin{array}{l}\text { Saya merasa sangat tertarik dan ingin tahu } \\
\text { tentang materi pelatihan yang akan diberikan. }\end{array}$ & 10 & 7 & 0 & 0 & 0 \\
\hline 2 & $\begin{array}{l}\text { Saya merasa kegiatan pelatihan semacam ini } \\
\text { hanya buang-buang waktu dan biaya saja }\end{array}$ & 0 & 0 & 0 & 6 & 11 \\
\hline 3 & $\begin{array}{l}\text { Saya merasa senang karena materi yang } \\
\text { diberikan sangat saya butuhkan dalam } \\
\text { pembelajaran matematika. }\end{array}$ & 9 & 8 & 0 & 0 & 0 \\
\hline 4 & $\begin{array}{l}\text { Saya merasa materi yang diberikan terlalu sulit } \\
\text { dan tidak bisa saya pahami. }\end{array}$ & 0 & 0 & 2 & 6 & 9 \\
\hline 5 & $\begin{array}{l}\text { Kegiatan pelatihan telah dilakukan dengan } \\
\text { metode yang tepat sehingga saya dapat } \\
\text { mengerti materi yang disampaikan. }\end{array}$ & 6 & 8 & 2 & 1 & 0 \\
\hline 6 & $\begin{array}{l}\text { Saya merasa terpaksa ikut pelatihan ini sebab } \\
\text { saya sangat awam dengan materi yang } \\
\text { diberikan. }\end{array}$ & 0 & 1 & 1 & 11 & 5 \\
\hline 7 & $\begin{array}{l}\text { Saya tidak merasakan manfaat yang signifikan } \\
\text { setelah mengikuti kegiatan ini. }\end{array}$ & 0 & 0 & 1 & 5 & 12 \\
\hline 8 & $\begin{array}{l}\text { Setelah mengikuti pelatihan ini, saya merasa } \\
\text { mendapatkan semangat dan inspirasi baru. }\end{array}$ & 13 & 4 & 0 & 0 & 0 \\
\hline 9 & $\begin{array}{l}\text { Saya akan mulai mengaplikasikan materi } \\
\text { pelatihan ini untuk menunjang pembelajaran } \\
\text { matematika. }\end{array}$ & 1 & 6 & 10 & 0 & 0 \\
\hline 10 & $\begin{array}{l}\text { Saya berharap kembali dilibatkan kegiatan yang } \\
\text { sejenis di waktu yang akan datang. }\end{array}$ & 12 & 5 & 0 & 0 & 0 \\
\hline
\end{tabular}

\section{Pembahasan}

Pelaksanaan kegiatan pengabdian masyarakat "Pelatihan Perancangan, Pembuatan, dan Penggunaan Media Adaptif Bagi Guru-Guru SLB Negeri 1 Klungkung" telah berjalan dengan baik dan mampu meningkatkan kemampuan guru dalam membuat dan menggunakan alat media adaptif bagi ABK.
Pada tahap persiapan, telah disusun materi pelatihan dengan kesiapan materi pelatihan telah mencapai tolak ukur yang ditetapkan yaitu 100\%. Pada tahap pelaksanaan pelatihan, telah dilaksanakan kegiatan pelatihan selama 1 hari yang dibagi dalam 5 sesi yaitu registrasi, pembukaan, pemaparan materi, praktik 
pembuatan alat peraga, simulasi penggunaan alat peraga dan penutupan.

Peserta yang terdaftar sebanyak 17 orang guru. Tingkat kehadiran peserta yang mencapai $100 \%$ menunjukkan ketertarikan guru-guru di SLB Negeri 1 Klungkung terhadap materi pelatihan. Peserta yang hadir juga mengikuti pelatihan secara penuh dan antusias. Hal ini nampak dari perhatian mereka yang terfokus pada narasumber ketika diberikan sesi pemaparan teori media adaptif. Begitu pula ketika sesi diskusi, peserta aktif bertanya, mengungkap permasalahan yang dihadapi dalam penggunaan alat peraga di kelas. Oleh karenanya dapat dikatakan bahwa "proses" pelaksanaan pelatihan telah berjalan dengan baik.

$$
\text { Hasil pengamatan kegiatan }
$$
merancang dan membuat media adaptif pada sesi 2 menunjukkan bahwa guru telah mampu merancang dan membuat media adaptif sederhana berupa fun exercise sesuai mata pelajaran yang diampu. Media fun exercise dipilih untuk dikembangkan karena mudah dibuah, murah dan terbukti efektif dalam meningkatkan aktivitas dan hasil belajar matematika siswa (Diningtias \& Mahmudah, 2019; Hikmah, 2016; Kelly, 2006; Mais, 2016; I Made Suarsana, 2019; Sugiarti, 2015). Selanjutnya dengan cara yang sama, kepada peserta dihimbau untuk mengembangkan pada materi yang berbeda. Kemampuan guru dalam menggunakan alat peraga juga sudah baik, terbukti mereka mampu melakukan simulasi penggunakan kartu bilangan yang mereka buat dan juga mampu mensimulasikan alat peraga lain yang dibawa oleh tim pengabdian. Dengan demikian kegiatan pelatihan telah berhasil meningkatkan kemampuan guru dalam merancang, membuat dan menggunakan alat peraga matematika SD.

Pada akhir kegiatan, peserta juga dimintai tanggapan terhadap pelaksanaan pelatihan melalui penyebaran angket. Ratarata skor tanggapan peserta diklat adalah 44,5 dari skor maksimum 50 atau sebesar $88.9 \%$. Hasil ini menunjukkan bahwa guru menanggapi positif terhadap pelaksanaan pelatihan. Guru merasakan senang karena materi yang diberikan sangat dibutuhkan dalam pembelajaran matematika dan mereka berharap kembali dilibatkan dalam kegiatan yang sejenis di waktu yang akan datang.

Secara umum program pengabdian pada masyarakat bertemakan" Pelatihan Perancangan, Pembuatan, dan Penggunaan Media Adaptif Bagi Guru-Guru SLB Negeri 1 Klungkung" telah mampu memecahkan permasalahan yang dihadapi guru-guru berkaitan dengan rendahnya kemampuan guru dalam merancang, membuat dan menggunakan media adaptif bagi ABK. Menurut Kepala SLB N 1 Klungkung, dalam sambutannya di akhir kegiatan mengatakan bahwa kegiatan pengabdian seperti ini sangat mereka perlukan dan sangat bermanfaat bagi mereka dan sekiranya memungkinkan mereka meminta agar di tahun-tahun mendatang pengabdian sejenis dapat lagi dilaksanakan dengan melibatkan Gugus II.

\section{KESIMPULAN}

Beberapa hal yang dapat disimpulkan dari hasil kegiatan PkM ini diantaranya (1) guru-guru SLB Negeri 1 Klungkung telah mampu merancang dan membuat alat peraga matematika sederhana berupa fun exercise, (2) guru-guru SLB Negeri 1 Klungkung telah mampu menggunakan media adaptif untuk pembelajaran $A B K$ berupa fun exercise, Obiko, Paras datar, Palu Guna, Media Kotak Stabil, dan PS Box, dan (3) guru-guru SLB Negeri 1 Klungkung memberikan tanggapan positif terhadap pelaksanaan pelatihan dengan persentase skor $88,9 \%$.

\section{UCAPAN TERIMA KASIH}

Ucapan terima kasih diberikan kepada (1) Kepala SLB Negeri 1 Klungkung atas kerjasama dan dukungan aktifnya, (2) DRPM Kemenristek-BRIN atas pendanaan kegiatan, dan (3) guru-guru peserta kegiatan dan siswa atas partisipasinya.

\section{DAFTAR PUSTAKA}

Aini Mahabbati, A.Pd., M. . (2013). Layanan Untuk Anak Berkebutuhan Khusus Dan Pendidikan Inklusif. 1-40.

Atanasius, E. P. (2016). Modul Guru Pembelajar Plb Tuna Daksa.

Bermasa, A. B. K. (2017). Abk bermasa 
depan cerah. 1-60.

Diningtias, R., \& Mahmudah, S. (2019). Metode Bercerita Berbasis Media Gambar Berseri Terhadap Kemampuan Pengenalan Konsep Waktu pada Anak Tunagrahita Ringan. Jurnal Pendidikan Khusus, 12(3).

Hikmah, N. (2016). Peningkatan hasil belajar matematika tentang penjumlahan dan pengurangan bilangan bulat melalui alat peraga mistar bilangan pada siswa kelas iv SDN 005 Samarinda Ulu. PENDAS MAHAKAM: Jurnal Pendidikan Dasar, 1(1), 80-85.

Kelly, C. A. (2006). Using manipulatives in mathematical problem solving: A performance-based analysis. The Mathematics Enthusiast, 3(2), 184193.

Mais, A. (2016). Media Pembelajaran Anak Berkebutuhan Khusus (ABK): Buku Referensi Untuk Guru, Mahasiswa Dan Umum. Pustaka Abadi.

Mais, A. (2018). Media Pembelajaran Anak Berkebutuhan Khusus. 192.

Putra, I. K. A. A. J., Suarsana, I. M., \& Suharta, I. G. P. (2020). PENGEMBANGAN BAHAN AJAR INTERAKTIF MATERI PECAHAN UNTUK SISWA SMPLB TUNARUNGU DENGAN PENDEKATAN MULTI REPRESENTASI. Jurnal Nasional Pendidikan Teknik Informatika: JANAPATI, 9(2).
Rahmawati, T., \& Suarsana, I. M. (2014). Analisis Pembelajaran Matematika di Sekolah Dasar Luar Biasa (SDLB) B Negeri Singaraja. Prosiding Seminar Nasional Optimalisasi Peran MIPA Dan Pendidikan MIPA Dalam Pengembangan IPTEKS. Singaraja: FMIPA Undiksha.

Suarsana, I. M. (2019). Pelatihan Perancangan, Pembuatan, dan Penggunaan Alat Peraga Matematika bagi Guru-Guru SD Gugus II Kecamatan Kubu. WIDYA LAKSANA, 8(2), 145-150.

Suarsana, I. M., Mahayukti, G. A., Sudarma, K., \& Yoga, N. B. A. (2018). Development of Interactive Mathematics Learning Media on Statistics Topic for Hearing-impaired Student I Made Suarsana a. International Research Journal of Engineering, IT \& Scientific Research, 4(6), p. 55-66. https://doi.org/10.21744/irjeis.v4n6.377

Sugiarti, S. (2015). Upaya meningkatkan kosa kata anak tunarungu melalui media variasi gambar pada siswa kelas V/B di SLB Negeri Surakarta. Seminar Nasional IImu Pendidikan UNS 2015. Sebelas Maret University.

Yuwono, I., \& Utomo, U. (n.d.). Pengembangan Pendidikan Bagi Anak Berkebutuhan Khusus Menghadapi Globalisasi Pendidikan Abad 21. 